\title{
O MONDOVINO DE CABEÇA PARA BAIXO: AS TRANSFORMAÇÕES NO MERCADO INTERNACIONAL DO VINHO E O NOVO EMPRESARIADO VINÍCOLA
}

\author{
Mauro Roese
}

\section{RESUMO}

A radical transformação do mundo empresarial vinícola desencadeada pela entrada de novos produtores e pela emergência de uma nova cultura, agora global, associada ao consumo do vinho, é o pano de fundo deste artigo. Tal transformação será analisada à luz das contribuições da nova Sociologia Econômica, bem como dos Estudos Sociais da Ciência e Tecnologia. A "popularização" do consumo é um reflexo do crescimento da oferta de vinhos de qualidade e da redução do preço do produto, o que foi possibilitado pela difusão de tecnologia e conhecimento. Esse processo ocasionou a ruptura do "segredo" da produção do vinho de qualidade: o que antes era privilégio de poucos produtores e regiões, herança guardada a sete chaves em famílias, passa a ser objeto de aprendizado e pode ser adquirido por meio do investimento em capacitação tecnológica. Como decorrência, novos produtores de vinhos de qualidade excelente surgem em países como Chile, Austrália, África do Sul, Brasil, entre outros. Essa transformação pode ser vista por dois ângulos: o da quebra da "aura" do vinho, com a conseqüente perda do privilégio de produtores $e$ consumidores, e o da produção social de um novo mercado que inclui novos produtores e possibilita o acesso de mais consumidores aos vinhos de qualidade. Essa expansão da oferta e do consumo de vinhos de qualidade, contudo, acompanha uma transformação das vinícolas tradicionais em objetos de culto e sinônimo de exclusividade e distinção. Estas últimas, por tornarem-se um grupo ainda mais restrito, tiveram seus vinhos ainda mais sobrevalorizados.

PALAVRAS-CHAVE: empresariado vinícola; construção social do mercado; Sociologia Econômica; Estudos Sociais da Ciência e da Tecnologia; mercado de luxo.

\section{INTRODUÇÃO}

O vinho é uma das bebidas mais antigas e, ao longo da sua história, além da sua grande importância econômica, ele sempre esteve associado a rituais, tanto religiosos como pagãos. A simbologia em torno do vinho sempre misturou-se à sua importância como mercadoria e hoje nenhuma outra bebida tem a sua imagem tão associada à tradição como ele.

Essa característica atribuiu especificidades ao fenômeno do crescimento do comércio internacional de vinho e à sua transformação em produto global. O crescimento do comércio internacional de vinho na última década foi significativo, mas, paradoxalmente, o consumo não tem crescido, pelo contrário, tem perdido espaço para outras bebidas, em especial para a cerveja, nas faixas de mercado de faixa etária mais jovem e de menor poder aquisitivo.
A globalização do mercado vinícola não se dá, portanto, pela expansão pura e simples do consumo e da oferta, mas pela criação de uma demanda global por produtos de alta qualidade, com alto valor agregado e com características bem específicas, visando um mercado diferenciado. O fascínio que essa bebida exerce sobre os consumidores e a mística que envolve seus produtores e as regiões onde o vinho é produzido e engarrafado pode explicar, em parte, esse fenômeno.

Uma das conseqüências da globalização é a transformação de produtos locais em globais, apoiando-se na idéia de que somente sendo produzido em um determinado local é que um produto possui certas características específicas e desejáveis pelo mercado. Em um olhar retrospectivo, observa-se que isso sempre ocorreu com o vinho produzido em regiões tradicionais, sobretudo com o vinho francês, que desde o início associou fortemente as características do produto com a sua a 
região de origem, o chamado terroir ${ }^{1}$. O vinho francês sempre foi um produto regional de consumo global (para poucos, bem entendido). $\mathrm{O}$ incremento do comércio exterior oportunizado pela abertura das economias nacionais gerou não somente um aumento do comércio internacional do vinho francês e a sua valorização em mercados emergentes, mas também um exemplo para outras regiões produtoras (Chile, Argentina), bem como um estímulo à vitivinicultura em novas regiões (Austrália, África do Sul).

Sendo assim, a globalização do consumo do vinho deu-se pela via da difusão de um conceito de excelência da qualidade do vinho, que se mantém associada à sua origem em uma região com reputação e tradição de produção de bons vinhos. $\mathrm{O}$ que mudou foi que se acredita agora que não somente regiões tradicionais produzem bons vinhos, mas que novas regiões produtoras podem conquistar seu espaço com a incorporação de tecnologia que permite a produção de vinhos de qualidade. A redução da defasagem tecnológica o tão invocado catching up, dos estudos sobre inovação em setores de ponta - aparece também nas análises de setores antes tidos como tradicionais ou de baixa intensidade tecnológica.

\section{A EXPANSÃO DA PRODUÇÃO, AS NOVAS REGIÕES PRODUTORAS E A "PERDA DA AURA” DO VINHO}

No processo de expansão da produção e do mercado global do vinho, a figura do enólogo, com formação técnica cada vez mais sofisticada, passa a ocupar uma posição de destaque no processo produtivo vinícola, avançando em um terreno que antes era monopólio e segredo guardado a sete chaves pelos vinhateiros tradicionais. Estes são donos e responsáveis técnicos pelos vinhedos e utilizam conhecimento tradicional, passado de pai para filho, há muitas gerações.

Esses vinhateiros, sobretudo em regiões onde a produção tem séculos de tradição, associam a produção do vinho a um processo quase mágico, em que as condições geofísicas e climáticas locais (o terroir), o conhecimento milenar e a tradição articulam-se e resultam em um produto singular, que possui uma "aura”. Fazer vinhos “com

\footnotetext{
1 O que ocorre de fato: vinhos produzidos com a mesma técnica e matéria-prima (determinada cepa vinífera), mas em regiões diferentes, apresentam características distintas.
}

aura” é um ofício que, na crença dos vinhateiros tradicionais, não pode ser ensinado em escolas formais, recriado em laboratórios ou transmitido por consultores. Ao vinho é atribuído um status de obra de arte, apesar dele desde sempre ter sido produzido em escala, e cada marca, cada safra, possui características únicas e a arte do vinhateiro é parte fundamental para a obtenção desse resultado.

Atualmente assistimos a um processo acelerado de corrosão dessa suposta aura do vinho e o vinhateiro tradicional, espécie em extinção, assiste à ascensão irresistível do consultor em enologia. O tipo ideal desse novo personagem no mundo do vinho é o enólogo francês Michel Rolland, considerado o mais requisitado e influente consultor de empresas vinícolas, que possui mais de uma centena de clientes pelo mundo afora.

Walter Benjamin falava em "perda da aura” ao se referir ao processo de reprodução e massificação da divulgação e consumo da arte, já que nesse processo a obra de arte perdia a sua característica de produto único e transformavase em bem de consumo em massa, no contexto de expansão do capitalismo (BENJAMIN, 1983, p. 10-15). Esse processo, até certo ponto inevitável, confronta-nos com o paradoxo entre a expansão do acesso a determinados bens e a perda das suas características originais, características estas, diga-se de passagem, que foram as motivadoras principais da sua transformação em objeto de desejo (e consumo) por segmentos sociais emergentes.

O vinho não é uma obra de arte no sentido literal, como as obras a que Benjamin referiu-se em seu texto clássico. Mas, para os vinhateiros tradicionais, o vinho tem a principal característica da obra de arte, segundo Benjamin, que é o fato de que cada marca, tipo e safra específica possui características únicas. O hic et nunc, que dá origem à aura da obra de arte, tem seu equivalente nas características inimitáveis de marcas e safras de vinho. Sendo assim, o vinho produzido em uma propriedade, que é o reino de gerações de vinhateiros, em uma região, guarda características próprias e únicas que não podem ser reproduzidas em outra situação e que ainda variam a cada nova safra.

Críticos das transformações no mundo do vinho, os vinhateiros tradicionais acusam os enólogos de tornar a vinificação um processo ex- 
clusivamente técnico, massificado, um conjunto de conhecimentos sem segredos, que qualquer um pode aprender e aplicar. Isso resulta em vinhos cada vez mais padronizados, produzidos em vinícolas em que as famílias proprietárias não são mais auto-suficientes no conhecimento do processo produtivo e apenas contratam técnicos especializados em vinificação.

Em termos gerais, a perda da aura do produto e a perda do monopólio do conhecimento por parte do produtor são temas recorrentes nas Ciências Sociais, quando se debruçam sobre as transformações no processo produtivo a partir do final do século XIX. Via de regra, a análise dessa problemática enfrenta o paradoxo de que a massificação e a burocratização da sociedade cria oportunidades de negócio e amplia o acesso ao consumo e mesmo à inclusão social. Esse era o ideal fordista, "todos podem ter um carro da cor que queiram, desde de que seja preto". Mas, por outro lado, esse fenômeno sepulta a individualidade e apaga as características personalizadas do produto. Esse paradoxo era uma constante nas análises da chamada Escola de Frankfurt, que critica a tendência massificadora e consumista do capitalismo, mas reconhece seu poder de romper a tradição.

Weber, em seus textos sobre a burocracia e ciência, destaca o lado modernizante que o estabelecimento de critérios técnicos para a organização e o acesso a postos de trabalho permite, mas, por outro lado, lamenta a padronização e a mediocrização que são conseqüências do mesmo processo (WEBER, 1979, p. 229-282).

A substituição do agente envolvido pessoalmente com a produção pelo técnico, funcionário que age mobilizado pela recompensa financeira, também é lamentado por Joseph Schumpeter ao constatar que o empresário inovador (que mais tarde seria chamado, em sua homenagem, de "empresário schumpeteriano") foi substituído pelo departamento de inovação. Um Schumpeter melancólico, ao referir-se a esse processo, fala em "emasculação do processo inovativo" (SCHUMPETER, 1984, p. 176). Mesmo em um enfoque marxista, como argumenta Braverman, a passagem do controle do "saber-fazer" do operário de ofício para a organização é vista por vezes como “degradação” (BRAVERMAN, 1981).

O que existe em comum entre todas essas análises é uma vertente de crítica ao desenvolvimento quando este implica na perda do controle do conhecimento por parte dos indivíduos ou segmentos sociais tradicionais e em detrimento do seu controle institucionalizado e formal. No mundo do vinho, o papel do consultor, bem como das escolas de enologia, passa a ser o de um difusor de práticas produtivas padronizadas e formalizadas que podem ser objeto de aprendizagem, transmitidas em escolas e aplicadas mesmo por quem está iniciando no ramo. Na visão desses novos agentes sociais, os resultados obtidos assim podem ser tão bons ou melhores que os obtidos pelos vinhateiros tradicionais.

No filme Mondovino ${ }^{2}$, Michel Rolland aparece como um poderoso e prepotente, mas ao mesmo tempo bem-humorado e simpático, consultor de enologia, que diz na frente da dona de uma vinícola que ela não precisa saber fazer vinho, pois ele sabe (e recebe muito bem para isso) e pode ensinar aos empregados da vinícola o seu ofício. Rolland materializa o ator social que está ocupando o espaço do vinhateiro tradicional e que recorre à técnica - pois não possui a tradição - de forma fria e comercial. Essa técnica é, por vezes, considerada ilícita pelos tradicionalistas, em comparação com as boas práticas milenares. Um exemplo muito lembrado, com desdém, pelos vinhateiros tradicionais é o das técnicas que permitem reduzir o tempo de maturação do vinho.

No fundo da polêmica, transparece o confronto entre dois modelos de organização da produção vinícola, o francês ${ }^{3}$, tradicional, baseado no conhecimento acumulado e guardado em segredo por gerações de vinhateiros, e o americano, pragmático, que compensa a pouca tradição com investimento em tecnologia e na qualificação formal dos enólogos.

Em um determinado momento, o modelo francês começou a ser questionado e passou-se a duvidar, sobretudo, que as duas formas de produzir tivessem resultados tão diferentes e em favor dos franceses. Elin McCoy, biógrafa de Robert Parker e pesquisadora de história do vinho, aponta um momento emblemático dessa dúvida: "O vinho americano e o consumidor de vinho americano continuaram sendo olhados com condescendência pelos franceses em meados da década de 1970,

2 Documentário dirigido por Jonathan Nossiter (MONDOVINO, 2004).

3 Ver mais a respeito em Garcia-Parpet (2004). 
quando a famosa, ou abominável, Degustação de Paris finalmente destacou que a América e os americanos poderiam ser mais importantes do que se tinha até então pensado, mesmo a despeito de não falarem francês. A degustação colocou alguns dos melhores vinhos da Califórnia em confronto com vinhos engarrafados franceses de grande prestígio e o lado americano venceu” (MCCOY, 2006, p. 43).

A referida degustação foi organizada por um inglês, Steven Spurrier, que tinha uma loja de vinhos em Paris e uma escola dedicada ao ensino de enologia e degustação. Ensinar a fazer vinho era visto pelos franceses como uma coisa inútil, ensinar técnicas de degustação, uma heresia. Mas o inovador inglês em seu exílio na terra do vinho, produto pelo qual ele era apaixonado, acabou contribuindo para o reforço da crença americana em que é possível ensinar a fazer e a beber vinho e, mais que isso, que quem aprende a técnica vinícola pode produzir vinhos tão bons ou melhores do que os que receberam os segredos da vinificação pela transmissão tradicional.

O modelo francês de organização da produção vinícola é extremamente refratário à inovação, bem como ao reconhecimento de que mesmo na França possam existir novas regiões produtoras de vinho capazes de obter o certificado de origem. O artigo de Marie-France Garcia-Parpet mostra como as regiões certificadas tradicionais resistem à inclusão de novas regiões dentro do território francês como dignas de receber o selo de origem controlada (GARCIA-PARPET, 2004).

Esse fechamento à inovação e à inclusão de novos produtores gerou recentemente dois movimentos no meio vinícola francês: 1 ) a crescente emigração de produtores para novas regiões como Austrália, África do Sul e Califórnia, onde eles têm acesso mais fácil à terra e uma regulamentação menos fechada; 2) o surgimento de movimentos regionais de contestação dessa organização tão fechada, como a associação de produtores da nova geração de Bordeaux, que se autodenomina Bordeaux Oxygène.

O fluxo migratório de produtores intensificouse, sobretudo a partir dos anos 1990, quando os vinhos franceses passaram a sofrer com a concorrência dos "vinhos novo mundo", Chile, Austrália, África do Sul e Estados Unidos. O impacto foi grande e causou um aumento desastroso dos estoques e redução dos preços dos vinhos das regiões tradicionais francesas.

Por outro lado, começou a ficar evidente que a manutenção do modelo tradicional de regulamentação do vinho na França estava prejudicando a maior parte dos produtores. O movimento Bordeaux Oxygène é formado pela nova geração de proprietários (herdeiros) de vinícolas na região de Bordeaux. A mais tradicional região vinícola do mundo abriga mais de 9000 propriedades produtoras de vinho, das quais uma ínfima parte - aquelas que produzem vinhos muito tradicionais e de altíssimo preço (acima de 1000 euros) - não é afetada pela transformação do mercado vinícola, pois tem mercado cativo e exclusivo. Entre as demais, cresce a percepção de que os regulamentos tradicionais da vinificação, a maior parte dos quais remonta à época de Napoleão, são um obstáculo à competitividade do vinho francês que disputa o mercado global. Muitos desses regulamentos são considerados anacrônicos pelas novas gerações de vinhateiros e enólogos, pois proíbem a utilização de técnicas que permitem reduzir o tempo de maturação do vinho e que conste no rótulo o tipo de uva com o qual o vinho foi elaborado ou referências às características gustativas do vinho.

Portanto, a questão da tradição versus inovação, vinhateiros tradicionais versus técnicos em enologia, pode ser vista, também, pela ótica dos protagonistas desses movimentos recentes - produtores de regiões emergentes, emigrantes e novas gerações das regiões tradicionais - que se sentem alijados pelas transformações no mundo do vinho e tolhidos pela tradição na sua luta para serem incluídos nesse mercado.

\section{O VINHO COMO DISTINÇÃO: A DIMEN- SÃO DO CONSUMO}

Independentemente da opinião dos vinhateiros, os consumidores sempre formularam sua idéia própria do que é um bom vinho, o que é uma característica fundamental do consumidor dessa bebida, pois eles não se reúnem apenas para beber, mas para conversar sobre as características do que é bebido. Mas a expansão da oferta de vinho e a ampliação dos segmentos sociais que tem acesso ao seu consumo vêm, como já nos referimos anteriormente, modificando o panorama da produção e do consumo, o que inclui mudanças no gosto do consumidor e na percepção 
que os produtores têm da influencia desse gosto na produção do vinho.

Em outras palavras: 1) o gosto do consumidor passa a ter uma influencia maior sobre as decisões dos produtores, o que influencia as características do produto final; 2) o gosto do consumidor passa a ter outras referências que não só a prova dos vinhos ofertados, mas também o acesso maior à informação prévia oportunizada pela publicidade, imprensa, literatura e à crítica especializada; 3) o consumo de vinho como distinção impele novos consumidores à busca dessa informação.

Sendo assim, a transformação do mercado do vinho e sua globalização tornam mais complexa a relação entre a produção e a demanda, sobretudo por tratar-se de um ramo em que o gosto do consumidor é o "calcanhar de Aquiles" do produto e objeto de disputa entre os próprios produtores e entre estes e os "formadores de opinião" do meio: "O ajuste entre oferta e demanda não é o simples efeito da imposição que a produção exerce sobre o consumo, nem o efeito de uma busca consciente mediante a qual ela antecipa as necessidades dos consumidores, mas o resultado de uma orquestração objetiva de duas lógicas relativamente independentes, ou seja, a dos campos de produção e a do consumo: a homologia, mais ou menos perfeita, entre os campos de produção especializados em que se elaboram os produtos e os campos (das classes sociais ou da classe dominante) em que se determinam os gostos, faz com que os produtos elaborados nas lutas de concorrência - travadas no espaço de cada um dos campos de produção e que estão na origem da incessante mudança desses produtos - encontrem, sem terem a necessidade de procurá-la propositalmente, a demanda que se elabora nas relações, objetiva ou subjetivamente, antagonistas que as diferentes classes e frações de classe mantêm a propósito dos bens de consumo materiais ou culturais ou, mais exatamente, nas lutas de concorrência que os opõem a propósito desses bens e que estão na origem destes gostos” (BOURDIEU, 2007, p. 215-216).

Em suma, Bourdieu desconstrói a dicotomia demanda/consumo, negando que uma determine a outra, e afirma a articulação das duas lógicas, que se dá de forma mais ou menos objetiva (à medida que ela é influenciada pela estrutura das relações entre segmentos sociais) e subjetiva (quan- do o gosto é influenciado por referências culturais, tradição, prestígio do produtor/marca).

O consumo massificado de "bens de luxo" é um fenômeno bem recente no mercado mundial e está associado a um relativo aumento da capacidade de consumo da classe média e ao crescimento da oferta global de produtos que antes eram destinados exclusivamente ao consumidor de altíssima renda. A massificação do luxo tem como reflexo o surgimento de empresas detentoras de marcas de produtos que tem seu nome associado à exclusividade, tradição, alta qualidade e luxo. Esses produtos passam a ser produzidos em escala maior e distribuídos globalmente, voltados para um mercado de alto poder aquisitivo (mas nem tanto quanto antes) e bem mais amplo. Para ter-se uma idéia, uma mesma empresa controla e distribui as marcas Veuve Clicquot e Chandon (champanhes), Louis Vuitton (bolsas), Montblanc (canetas, jóias), entre outras. Esse é um fenômeno do crescimento do mercado de produtos que conferem "distinção" aos seus possuidores, pois exigem do consumidor, além do dinheiro para a aquisição, sofisticação e conhecimento, o que agora não é apenas um atributo dos que possuem poder aquisitivo para tal, mas também dos que querem usufruir do prestígio que é atribuído supostamente ao seu possuidor.

Da mesma forma, o consumo do vinho de qualidade sempre foi uma forma de diferenciação entre consumidores de bebida e um indicador de distinção social. Uma característica diferencial do consumo do vinho é o fato dele ser uma bebida que "exige" do consumidor conhecimento prévio para que ele seja degustado "corretamente", na temperatura ideal, na taça de formato adequado e que o tipo de vinho esteja em harmonia com o cardápio escolhido. $\mathrm{O}$ vinho pode ser assunto nas mesas de jantar, o conhecimento sobre o tema pode ser invocado como distinção. O florescimento da crítica especializada, da literatura sobre vinhos e degustação, dos cursos e do comércio de produtos associados ao seu consumo (adegas climatizadas, taças e outros acessórios), de certa forma é uma decorrência da necessidade de uma certa qualificação do consumidor para a sua entrada no mundo do vinho.

Como nos demais produtos do mercado do luxo e da distinção, algumas marcas de vinho que alcançaram prestígio após anos ou, por vezes, séculos de tradição e conhecimento, acumulado 
por gerações de vinhateiros, são adquiridas por grandes empresas, pelo simples fato de serem uma marca com prestígio. Nesse processo, muitas vezes, os antigos detentores do conhecimento especializado são substituídos por técnicos e as características originais do vinho são adaptadas ao paladar do novo mercado mais amplo e padronizado, embora nem tão amplo, nem tão padronizado, quanto o mercado orientado pelo ideal fordista.

Na expansão do consumo de um produto antes restrito a poucos, a opinião dos críticos especializados e a ampla divulgação dos seus pareceres e das notas atribuídas aos vinhos, cumprem um duplo papel: o de formar opinião entre os consumidores e o de criar uma referência pública para os produtores que vêem seus vinhos serem comparados aos concorrentes e obterem notas maiores ou menores. Os críticos mais prestigiados e, por isso mesmo, mais influentes, acabam fazendo o papel do que, em administração, chama-se de benchmarking, que nada mais é do que a criação de espaços em que as empresas possam comparar seu desempenho com as ditas empresas mais competitivas. Outro elemento que permite aos produtores essa comparação são as premiações em concursos internacionais de vinho, o que sempre existiu, mas que recentemente tornou-se ponto de referência para os produtores procurarem ajustar o paladar do seu vinho às tendências ali apontadas pelos vinhos premiados.

A esse benchmarking do vinho é, por vezes, atribuída a culpa de um suposto processo de padronização e "mediocrização" dos vinhos disponíveis no mercado global. Por mais que se possa argumentar que uma nota menor não necessariamente significa que um vinho é pior do que outro, não se pode negar que isso influencia sensivelmente os hábitos dos consumidores e, por conseqüência, as estratégias mercadológicas dos produtores na direção da conquista do paladar dos seus consumidores. Pode-se argumentar que, na linha de pensamento de Gereffi, a cadeia produtiva do vinho vem passando da situação de uma cadeia coordenada pela oferta, para uma cadeia coordenada pela demanda (GEREFFI,1994, p. 14), o que é perfeitamente plausível para a um produto que é alvo de acaloradas discussões entre consumidores, críticos especializados e produtores tradicionais.

Por outro lado, temos que admitir que não é a comparação que cria a padronização, mas a ex- pansão do mercado do vinho que acaba gerando a necessidade do consumidor neófito buscar alguma referência sobre um produto, que apesar de prestigiado e pleno de tradição, não faz parte de sua história nem de suas referências culturais. Do ponto de vista do consumidor que cresceu em uma família que tinha entre seus hábitos a degustação de vinhos de alta qualidade, podemos falar que este assiste a um processo de padronização e de "perda de aura" de um produto que antes era um de seus símbolos de distinção. Mas, nesse mesmo processo temos os novos consumidores, a quem a expansão do mercado global do vinho e os novos hábitos de consumo a ele associados acenam com um convite para o ingresso em um novo mundo: o Mondovino.

\section{MONDOVINO: VILÕES DA GLOBALIZA- ÇÃO DO VINHO VIRAM PERSONAGENS NO CINEMA}

O documentário que já citamos, Mondovino, de Jonathan Nossiter, coloca na tela do cinema os personagens dessa história. No filme, as vítimas da globalização, os vinhateiros tradicionais, trocam farpas e ironias com Michel Rolland, o mais requisitado consultor de empresas vinícolas da atualidade, Robert Parker, o mais influente crítico de vinhos do mundo, e Robert Mondavi, tido como protótipo do moderno (e implacável comprador de vinícolas) empresário do mundo do vinho. O filme, extremamente bem dirigido e produzido, ganhou imediata acolhida da crítica e foi aclamado no festival de Cannes, em 2004.

De certa forma, a obra toma partido em favor da tradição e apresenta os novos personagens como vilões e, por vezes, como cínicos e inescrupulosos. Por outro lado, o filme deixa entrever o já aqui referido "paradoxo frankfurtiano" entre a expansão e a inovação da produção e consumo do vinho e o quase inexorável desaparecimento do personagem que deu origem a toda essa história: o apaixonado vinhateiro tradicional e seus vinhos com aura. Na verdade, se tudo ficasse como antes, não teríamos paradoxo, nem produtores milionários, críticos e consultores prepotentes, nem tampouco milhões de novos consumidores com acesso ao mundo do vinho.

Tomamos o título do filme emprestado para ilustrar que o paradoxo de fato existe e a modernização virou a cadeia produtiva e o mercado do vinho de cabeça para baixo. A grande inversão foi a de que o mercado, outrora pequeno e consumi- 
dor passivo da obra de arte do vinhateiro, passa a ser um agente que intervém (em demasia) diretamente na sua arte. Nesse processo, a massificação é inevitável, pois o mercado cria referências de qualidade e preço que são externas ao processo produtivo, ou seja, não é mais o vinhateiro que faz o vinho que quer e vende-o ao preço que bem entende. A cadeia produtiva deixa de ser regida pela oferta e passa ao comando da demanda (GEREFFI, 1994, p. 14).

No filme, ao crítico especializado americano Robert Parker é atribuída a façanha de em um mesmo dia acabar com a reputação de um vinho tradicional e colocar vinhos emergentes no pedestal. O poder de influência de Parker e sua publicação bimensal The Wine Advocate 4 é acusado de direcionar o gosto do consumidor para padrões de paladar padronizados e mais próximos das características dos vinhos emergentes ou, mais especificamente, os produzidos pelas novas empresas, de regiões e países não tradicionais.

Aqui, a crítica especializada cumpre um papel estratégico, ao substituir o consumidor no papel de provar, analisar e criticar centenas de marcas de vinho e depois classificá-las hierarquicamente e publicar tudo isso em revistas ou jornais especializados. Mesmo que esta seja idônea e, até certo ponto, sensível à diversidade e tente não levar em conta a fama e o preço do vinho, ela acaba inevitavelmente contribuindo para a criação de um padrão de paladar que influencia consumidores e produtores.

Por outro lado, como o consumidor poderia provar e analisar centenas de marcas e safras de vinho? A sua única possibilidade de orientação nesse amplo leque de oferta é o filtro da crítica especializada que obtém espaço privilegiado na mídia. Nesse sentido, o poder a esta atribuído é real: a partir do momento em que o mercado torna-se a única forma de termos acesso a um determinado produto, somos submetidos aos que tem o poder de barrar ou franquear o acesso a ele. Podemos pensar que, assim como o crítico pode deixar de provar uma marca ou mesmo provar e não gostar, o editor pode negar-se a publicar uma obra-prima. Essa dimensão cruel do mercado é real.

4 Nome que faz referência à formação acadêmica de Parker em Direito.

\section{MONDOVINO DE CABEÇA PARA BAIXO: A DIMENSÃO DA INCLUSÃO DE NOVAS RE- GIÕES, PRODUTORES E CONSUMIDORES NEÓFITOS}

Pode-se argumentar que o conflito é apenas representado por esses atores sociais tão eloqüentes que o filme apresenta e que o roteiro dessa história foi escrito pela globalização em geral e pela expansão da oferta e do hábito de tomar vinho. A problemática da expansão do mundo do vinho, da provável padronização e perda do halo do produto, contudo, pode ser vista de outras perspectivas que não somente a desses atores: além dos grandes produtores emergentes, dos críticos com alto poder de formação de opinião, dos consultores poderosos e dos vinhateiros alijados do seu papel tradicional, existem novas regiões produtoras, pequenos produtores que retomam suas tradição familiares na atividade vinícola e consumidores que entram num mundo antes inacessível aos mortais.

Nesse contexto de transformação do vinho em produto regional de consumo global, a abertura desse mercado para novas regiões produtoras passou pelo rompimento com a idéia de que apenas a tradição permite a produção de vinhos de alta qualidade e que somente em determinadas regiões isso é possível. Emerge atualmente a noção de que isso pode ser objeto de aprendizagem, que o investimento em tecnologia e na capacitação de produtores também pode resultar na produção de vinhos de qualidade similar aos produzidos nas regiões tradicionais. Portanto, a produção de vinhos de alta qualidade e aptos a competir nesse mercado seleto pode ser "criada", ser fomentada por investimento em ciência e tecnologia aplicadas a esse fim, em suma, pode ser um alvo relevante para políticas públicas de inovação.

A globalização tem muito a ver com esse processo. Logicamente, ninguém importa vinho "ruim": o vinho de mesa (cada vez mais um eufemismo para vinhos de baixa qualidade) é produzido e consumido regionalmente. O mercado para o vinho de baixa qualidade não é afetado pela globalização, mas pela mudança dos hábitos de consumo e pela redução da diferença de preço em relação aos vinhos de qualidade. Por outro lado, quem produz vinho de boa qualidade é profundamente afetado pela globalização do mercado vinícola, pois vê-se obrigado a competir em preço e qualidade com os bons vinhos importados. Sendo 
assim, observa-se um movimento claro em regiões que produziam vinhos de qualidade razoável, as quais passam a ter que investir em capacitação, visando em um primeiro momento sobreviver à concorrência dos importados e, mais recentemente, aspirar a uma fatia no mercado global.

Isso vem ocorrendo em regiões que antes eram voltadas para mercados regionais ou nacionais, como a Califórnia, nos Estados Unidos, a região do D’Ouro, em Portugal, regiões produtoras do Chile e da Argentina e a região vinícola da serra gaúcha, no Rio Grande do Sul. O vinho de alta qualidade precisa ser produzido e engarrafado na própria região onde as uvas são cultivadas, pois isso possibilita que a qualidade da matéria-prima seja acompanhada de perto pelo produtor do vinho e que seja criada uma identidade entre as características e a qualidade do vinho e a região onde ele é produzido - só assim a região transforma-se em uma "marca”. Isso ocorre há muito tempo em regiões e cidades européias, que registram seu nome como marca e supervisionam, classificam e certificam (com uma indicação de procedência) os vinhos produzidos em regiões tradicionais, como Bordeaux e Saint Emillion, na França, Valpolicella e Frascatti, na Itália.

Outro fenômeno recente, envolvendo a mística que associa a qualidade do vinho com o local onde ele é produzido, é o florescimento do turismo em regiões vinícolas, que oferecem como atração, além da degustação e venda de vinhos, a visita às vinícolas, a gastronomia e a cultura locais. Na esteira desse processo, florescem mercados associados ao crescimento do prestígio da bebida, com a venda de acessórios para a conservação do vinho (adegas climatizadas), para a degustação (decantadores, taças) e do conhecimento necessário a uma degustação competente (cursos, literatura especializada). Em outras palavras, o mercado do vinho, apesar de em termos relativos não ser muito expressivo (participação no Produto Interno Bruto, receita de exportação), é um segmento com um dinamismo muito significativo e que está contribuindo para a dinamização de economias locais.

VI. UM CASO DE INCLUSÃO E REGENERAÇÃO DE ECONOMIA VINÍCOLA LOCAL: TRADIÇÃO E INOVAÇÃO NO VALE DOS VINHEDOS

Na região reconhecida como a maior produtora de uva e vinho do Brasil, localiza-se o distrito de Vale dos Vinhedos, que faz parte do município de Bento Gonçalves. Há nessa região a presença de muitas vinícolas, a maioria das quais pequenas empresas $^{5}$ de origem familiar, administradas por descendentes das famílias de imigrantes italianos que passaram a estabelecer-se no local nas últimas décadas do século XIX.

Além da sua tradição na produção de vinhos, o Vale dos Vinhedos vem investindo em infra-estrutura turística na tentativa de incrementar essa atividade econômica associada à produção do vinho, procurando aproveitar o crescimento do consumo, do prestígio da bebida e da "onda" de turismo temático a ela referenciada. Ao longo das estradas que cortam a vegetação característica da encosta da serra gaúcha, encontram-se diversas vinícolas, hotéis, restaurantes, pousadas e queijarias. Sendo assim, as vinícolas localizam-se junto a uma zona de grande potencial turístico, reforçado pelo simbolismo atribuído ao vinho, o que gera uma imensa curiosidade nas pessoas que querem saber onde e como são produzidos os vinhos que eles consomem. Muitas vezes, meros turistas transformam-se em consumidores e multiplicadores do hábito, após uma vista a esses locais. Assim, a imagem da bebida é apreendida através de um significado inerente à região produtora: o vinho pode até não precisar desse entorno turístico e tradicional para ser produzido, mas para ser vendido, sim.

Observa-se que mesmo em empresas vinícolas que ainda estão firmemente assentadas sobre uma organização familiar, é crescente a inovação por meio da aquisição de equipamentos modernos, do plantio de castas viníferas, da contratação de técnicos em enologia e da qualificação de sua mão-de-obra. Essa inovação na região articula-se a um resgate de tradições que haviam sido perdidas ao longo de décadas de perda de prestígio da produção de vinho.

A produção vinícola na região da serra gaúcha começou com a chegada dos primeiros imigrantes e destinava-se, inicialmente, ao consumo doméstico e ao mercado local. Mas rapidamente a uva e o vinho transformaram-se em produtos vendidos para outras regiões do estado e do país. Ao

5 Do total de vinícolas, 63,5\% são caracterizadas como pequenas empresas, $31 \%$ enquadram-se como de médio porte e apenas 5,5\% são consideradas como empresas de grande porte (BRASIL. MINISTÉRIO DO TRABALHO E EMPREGO, 2005). 
longo do século $\mathrm{XX}$, foi estruturando-se na região um importante pólo produtor de vinho. Apesar do clima e da altitude da região da serra gaúcha não serem os ideais à produção de uva e vinho, a determinação dos colonos e o costume trazido da Itália prevaleceu e consolidou a região como a maior produtora nacional (em volume e valor). Mas a divisão do trabalho que se estabeleceu nessa cadeia produtiva não foi a adequada para a produção de vinhos de alta qualidade, o que exige, em primeiro lugar, o cultivo de uvas de castas viníferas e isso na própria vinícola em que o vinho é produzido. Contrariamente, ao longo do século $\mathrm{XX}$, a maior parte dos produtores locais foi especializando-se no fornecimento de uva para empresas e cooperativas vinícolas, que padronizam a matéria-prima oriunda de diversos produtores com qualidades muito heterogêneas, homogeneizando o produto por meio da adição de açúcar de cana e por processos químicos, o que resulta em um vinho de baixa qualidade. Além disso, como os produtores de uva não vendem somente para as vinícolas, eles cultivam as chamadas "uvas de mesa”, apropriadas para o consumo da fruta, mas não para a produção de vinho. Essa é a chamada produção de "vinhos de mesa", um eufemismo para vinho de baixa qualidade, o qual tem um mercado garantido entre os consumidores que, sem preocupação com a qualidade, procuram baixo preço e alta quantidade, características eternizadas pelos "garrafões" de cinco litros, vendidos por um preço muito acessível.

Por outro lado, os produtores de uva sempre queixaram-se dos baixos preços pagos pela uva, situação que dificilmente mudaria, pois aos produtores de vinho em alta escala interessa o fornecimento de uva em grande quantidade e por um baixo preço, não importando a qualidade do produto. Os produtores de uva, inclusive, queixavamse de que as vinícolas atrasavam o recebimento da matéria-prima para que esta perdesse qualidade e baixasse de preço. Esses elementos contribuíram para o crescimento da noção de que só agregando valor à uva (ou seja, fazendo também o vinho), os produtores poderiam almejar melhores resultados econômicos.

Esse arranjo de características físicas do local, divisão do trabalho e exploração de um mercado de consumo em massa de produtos de baixa qualidade predominou até o final dos anos 1980, quando entrou em cena o vinho como produto global, processo ao qual já nos referimos nas sessões anteriores. A partir de então, começam a aparecer no mercado brasileiro vinhos importados a um preço acessível, o que acabou revelando um mercado em potencial para o vinho de qualidade.

Para disputar esse mercado e competir com o vinho importado, observa-se a partir de meados dos anos 1990, um movimento no sentido de reconversão da pequena produção local caracterizado por: 1) uma mudança na divisão social do trabalho na cadeia vinícola, com a fusão das etapas da produção da uva e do vinho na mesma empresa; 2) o surgimento da possibilidade de opção pela produção do vinho de "qualidade padrão mundial”, o que implica em produção em escala bem menor, mas com muito valor agregado.

Nesse contexto, a "indicação de procedência" (certificação de que um vinho é produzido com uvas de uma determinada região e engarrafado na origem) torna-se um instrumento de grande importância. A Lei da Propriedade Industrial, de 1996, criou o marco legal que permitiu a criação desse tipo de certificação no Brasil. A partir daí, iniciase um movimento que, aproveitando o crescimento do comércio internacional do vinho e o crescimento, no Brasil, do mercado potencialmente consumidor de vinho "qualidade padrão mundial", passa a investir na consolidação do segmento da indústria vinícola que vai apostar na produção de vinhos aptos a disputar o mercado global ou a pelo menos competir no mercado nacional com os vinhos importados.

O caso do Vale dos Vinhedos é um exemplo de mobilização de produtores locais que deu origem a uma marca registrada. A partir da criação de uma associação de produtores de uva e vinho, hotéis, pousadas e restaurantes buscou-se revitalizar a economia local com base na articulação entre a produção de vinhos de alta qualidade e a valorização da tradição e cultura do local, além do estímulo ao turismo e à exportação de vinho.

Em 1995, é criada a Associação dos Produtores de Vinhos Finos do Vale dos Vinhedos (Aprovale), iniciativa de seis vinícolas locais que tinha como objetivo principal qualificar a produção vinícola da região e, sobretudo, desenvolver um projeto de certificação da origem dos vinhos ali produzidos, nos moldes de regiões similares na Europa. Ao longo de sua breve história, a Aprovale incorporou também empresas não vinícolas, con- 
tando hoje com 32 vinícolas e 24 associados não produtores de vinho, entre hotéis, pousadas, restaurantes, artesanatos, queijarias e outros. As vinícolas do Vale dos Vinhedos produziram, em 2006, 6,9 milhões de litros de vinhos finos, o equivalente a 9,2 milhões de garrafas (APROVALE, 2005).

A Aprovale ingressou, em 1997, com um pedido junto ao Instituto Nacional de Propriedade Industrial (INPI), a fim de obter o registro da Indicação de Procedência do Vale dos Vinhedos (IPVV), que foi aprovada em 2002. A partir da comprovação da procedência e de uma série de análises dos produtos, os vinhos ali produzidos (por produtores associados) podem ostentar nos seus rótulos o selo que comprova sua procedência do Vale dos Vinhedos. Recentemente, a IPVV conquistou o reconhecimento pela Comunidade Européia (CE), como região de origem controlada. Foi a primeira região não européia a conquistar esse reconhecimento, o que permite que os vinhos ali produzidos possam ser comercializados nos países pertencentes à CE.

A criação da "indicação de procedência" envolveu, além da mobilização da comunidade e dos produtores da região, a Universidade de Caxias do Sul (UCS), a Empresa Brasileira de Pesquisa Agropecuária (Embrapa) e outros centros de pesquisa e ensino regionais, que se envolveram na demarcação e no levantamento das características físicas da região, na criação de uma infraestrutura para análise da qualidade e da autenticidade do vinho ${ }^{6}$.

A inovação na produção vinícola da região não rompeu, contudo, com a tradição da indústria vinícola de base familiar, pelo contrário, ela foi instrumento de preservação da gestão familiar das empresas e da manutenção de famílias unidas em torno da atividade que as caracterizou desde a chegada da primeira geração à região, no século XIX.

A relação entre inovação e tradição não é a de duas esferas dicotômicas que se negam, mas a de pares que se complementam e alimentam a mobilização dos esforços dos agentes econômicos locais. Isso ocorre porque a produção do vi-

\footnotetext{
6 A detecção de fraude em vinhos após a produção não é tarefa simples e exige alto investimento em laboratórios e recursos humanos. Somente com essa análise é que um vinho pode candidatar-se à certificação de origem.
}

nho no Vale dos Vinhedos está intimamente vinculada ao cultivo das tradições familiares associadas à sua origem italiana. Mesmo frente às modernizações na vinicultura, as raízes do imigrante italiano estão presentes na configuração do espaço em que o vinho é produzido. A inovação ocorreu com a transformação no processo de fabricação do vinho, a partir da incorporação de máquinas e de recursos humanos qualificados, na reconfiguração da divisão do trabalho na cadeia produtiva do vinho e na mudança no conceito do que é um bom vinho. Isso transpareceu na série de entrevistas que realizamos com diversas gerações de produtores em vinícolas familiares da região, das quais extraímos alguns trechos ilustrativos que apresentaremos a seguir.

A produção de vinho é um elemento fundamental da construção da identidade das famílias da região e isso é percebido e valorizado em todas gerações:

"Aqui em casa era tudo [uva] comum, aqui tinha parreira de 120 anos. Desde quando vieram da Itália e trouxeram de lá as mudas e, passou um tempo, já tinha as muda aqui. Basta dizer que por isso que sobrou um monte de vinho e construíram a igreja” (vitivinicultor, 73 anos; quarta geração de descendente de imigrantes italianos).

"Foi nosso bisavô quem começou. Esses vinhedos têm em torno de 100 anos. Nós encontramos raízes com quatro metros de profundidade. Foi passando de geração para geração" (viticultor e administrador, 32 anos; sexta geração de descendente de italianos).

Os mais velhos não se imaginam fazendo outra coisa, muito embora nem sempre a uva e o vinho tenham sido a principal fonte de renda. Simbolicamente, ela é muito valorizada pelas famílias, fato do qual eles têm consciência:

"Nós trabalhávamos mais com vinho comum. [A empresa] está registrada em 1946, nós fazíamos o vinho, mas vendíamos o vinho para a Aurora, para a Dreher, para vinícola grande, que eles tinham nome. Nós fazíamos vinho artesanal, vinho da colônia, com o talão do agricultor. Nós plantávamos de tudo. Não era só uva. Hoje em dia se trabalha mais com o cultivo da uva. Hoje em dia, para falar a verdade, nós não temos nada a não ser uva. Temos uma hortinha quebra-galho. Se tinha porco, vaca, galinha, trigo, milho, tinha de tudo, se trabalhava nisso aí. A parreira era pou- 
ca, não era grande o consumo também. Eu cansei de ter uva na parreira e ninguém queria, deixava lá. Não era consumo, hoje que surgiu bastante vinícola, mais consumo, mais divulgado o vinho. Antigamente não era tanto assim. Nós plantávamos o trigo [...], mas agora, aqui, em qualquer lugar bonito, se planta parreira, porque nós temos máquina para isso também, máquinas para tratar [...] então se torna rápido o trabalho" (vitivinicultor, 73 anos; quarta geração de descendente de italianos).

Em determinado momento, em algumas famílias, começa a nascer a percepção de que a saída para a manutenção do vinho como principal negócio da família é o investimento em inovação. Esse processo é desencadeado no interior das próprias famílias, por meio do diálogo entre as gerações:

"Tem algumas coisas que a gente tem problemas até hoje. Por exemplo, o pai é da geração que trabalhava, plantava para a quantidade e não para a qualidade. Foi bem complicado para convencer ele de que tínhamos que mudar os vinhedos, os sistemas de produção e trabalhar com uva vitivinífera se quiséssemos vislumbrar um futuro melhor em termos [empresariais]. Isso foi bem complicado para articular essas questões [...] imagina 'seu avô viveu daquela forma, seu bisavô também, por que nós vamos ter que mudar?’ Por isso se manteve esta área [parreiras de uva comum], pela história, em função também para mostrar um pouco como era no passado e como é hoje" (vinicultor e administrador, 32 anos; sexta geração de descendente de italianos).

Mas os mais velhos, apesar de certa perplexidade em relação às transformações, têm uma nítida percepção dos obstáculos à manutenção da sua atividade tradicional:

"Nós temos um problema sério com a importação, porque está entrando muito vinho da Argentina, do Chile [...] Lá eles produzem vinho mais fácil que nós aqui, nosso clima aqui não é tão favorável, mas assim mesmo nós estamos [produzindo] [...]. Tem uns que dizem que é melhor o importado, outros dizem que é o nosso aqui. Nós temos as mesmas mudas que eles tem, nós temos as mesmas máquinas que eles tem” (vitivinicultor, 73 anos; quarta geração de imigrantes italianos).

Apesar das dificuldades, até o final dos anos 1980, a produção local sustentava-se e até permi- tia algum investimento em melhorias, no entanto, as transformações macroeconômicas ocorridas no Brasil, em meados dos anos de 1990, interferiram no desenvolvimento da região, como relata um dos entrevistados:

"Um momento de uma grande crise no setor, aqui, [foi] com a abertura dos mercados do governo Collor. O Brasil não estava preparado para competir com os produtos de qualidade, com o preço que se produzia aqui para fazer frente aos importados que começavam a entrar. Tinha um vinho com uma garrafa azul, alemão, que praticamente quebrou as grandes empresas e as cooperativas. A vinícola [de] que nós éramos associados deixou de pagar duas safras seguidas para nós e a gente vivia disso, da venda da uva [...]. Então nós fomos nos desestimulando com o trabalho com a viticultura e depois de muita conversa, família grande, junto com a do meu tio, a gente optou por profissionalizar as atividades e termos nosso próprio negócio. Agregar valor. A nossa história é muito parecida com as das demais empresas daqui. E, claro, o cara olha assim pro lado e vê o vizinho que está com o negócio, aí outro abre também, aí estimula também a dar seqüência ao seu próprio negócio, a agregar valor” (vinicultor e administrador, 32 anos; sexta geração de descendente de italianos).

Cabe ressaltar que as novas gerações que estão assumindo os negócios familiares nas últimas décadas, fazem-no em condições bem diferentes das vivenciadas pelos antepassados pioneiros. As novas gerações possuem muita qualificação, obtida em cursos universitários, seja na área de enologia e química, seja na área de engenharia, economia e administração. Grande parte das novas gerações de empresários locais, em determinado momento, deixaram a região para estudar em universidades locais ou na capital. As perspectivas desanimadoras dos negócios familiares impunha a esses jovens o objetivo de qualificar-se e estabelecer-se no meio urbano, contribuindo para o sustento dos que permaneciam no campo. Aos poucos esse processo foi sendo revertido: muitos dos que buscavam na cidade a qualificação para gerir a produção vinícola decidem voltar às suas origens e assumir os negócios da família (encontramos até casos de pessoas que, mesmo depois de bem-estabelecidas na cidade, retornaram para os locais de origem). Esse processo foi motivado por dois fatores: 1) o desejo de viabilizar econo- 
micamente uma atividade que cumpre um papel fundamental na identidade da sua família e comunidade; 2) o vislumbre de uma possibilidade concreta de obter-se essa viabilidade pela reconversão da empresa familiar para a produção de vinho de qualidade e pela exploração do turismo e outras atividades ligadas ao vinho.

Uma característica importante da região é de que a maior parte das empresas que inovaram seguem com o perfil familiar encontrado em suas origens. Algumas empresas cresceram muito, exportam e têm grande faturamento, mas mantêm a gestão familiar. As características da produção do vinho de qualidade também podem favorecer o crescimento do negócio sem que sejam perdidas as suas características de gestão familiar.

Deparamo-nos, neste estudo de caso, com uma situação inversa à descrita anteriormente. Em regiões em que existe uma produção tradicional, como a da serra gaúcha, porém sem o prestígio e a aura de regiões como as que o filme Mondovino mostra, a globalização abriu uma janela de oportunidades para pequenas vinícolas - e para grandes empresas locais também - inserirem-se de uma forma positiva no mercado vinícola global, revitalizando a economia local e estimulando o resgate de tradições familiares.

\section{CONCLUSÕES}

Procuramos nesse texto ressaltar o paradoxo evidenciado pela globalização do mercado de vinho de alta qualidade, sobretudo na ameaça que ela representa de extinção da figura do vinhateiro tradicional e da "aura" do vinho. Por outro lado, o que é uma ameaça para o vinhateiro é uma janela de oportunidades para vinicultores de regiões emergentes e um franqueamento do acesso ao consumo do vinho de qualidade a um segmento maior e mais diversificado do mercado de consumo.
Na análise da polêmica entre produtores tradicionais e produtores emergentes, consultores e críticos de vinho, observamos que os dois lados, no fundo, defendem posições em modelos distintos de produção e consumo de vinho. O pragmatismo americano, capitaneado pelo crítico Robert Parker, defende que tradição e preço não são indicadores de qualidade, e para isso ele propõe-se a provar e a dar pareceres de vinhos comprados diretamente no ponto de venda e provados sem que o degustador saiba a marca e a origem. A prática da degustação "no escuro", antes tida pelos franceses como abominável, vem demonstrando que mesmo o degustador mais qualificado não consegue diferenciar os vinhos "com aura" dos "sem aura”, a menos que ele tenha acesso ao rótulo do vinho antes da prova.

Por outro lado, a chamada "aura” dos vinhos tradicionais ainda influencia o consumidor que tem poder aquisitivo para tal, o que nos autoriza a afirmar que a modernização reduz o espaço do vinhateiro tradicional, mas não o elimina. Em outras palavras, houve uma expansão da oferta e do consumo de vinhos de qualidade e a transformação das vinícolas tradicionais em objetos de culto e sinônimo de exclusividade e distinção. Estas últimas, por tornarem-se um grupo ainda mais restrito, tiveram seus vinhos sobrevalorizados.

No grupo das vinícolas emergentes, de regiões sem grande tradição, como é o caso do Vale dos Vinhedos, observa-se que o crescimento do mercado do vinho possibilitou uma certa regeneração da produção local, o que permitiu, por um lado, o surgimento de vinícolas de grande porte que investem muito e exportam e, por outro, a revitalização de vinícolas artesanais que se dedicam à produção de vinhos em pequena escala, associada à atividade do turismo temático destinado à formação de novos enófilos.

Mauro Roese (roese@ufrgs.br) é Doutor em Política Científica e Tecnológica pela Universidade de Campinas (Unicamp) e Professor do Departamento de Sociologia da Universidade Federal do Rio Grande do Sul (UFRGS).

\section{REFERÊNCIAS BIBLIOGRÁFICAS}

BENJAMIN, W. 1983. A obra de arte na época de suas técnicas de reprodução. In : BENJAMIN, W. Textos escolhidos. São Paulo : Abril Cultural.
BOURDIEU, P. 2007. A distinção - crítica social do julgamento. São Paulo : Edusp. 
BRAVERMAN, H. 1981. Trabalho e capital monopolista. Rio de Janeiro : Zahar.

GARCIA-PARPET, M.-F. 2004. Mundialização dos mercados e padrões de qualidade: "vinho, o modelo francês em questão". Tempo Social, São Paulo, v. 16, n. 2, p. 129-150, nov.

GEREFFI, G. 1994. Global Commodity Chains and Third World Development. Durham, mimeografado.

MCCOY, E. 2006. Robert Parker : o imperador do vinho. Rio de Janeiro : Elsevier.

SCHUMPETER, J. 1984. Capitalismo, socialismo e democracia. Rio de Janeiro : Zahar.
WEBER, M. 1979. Burocracia. In : WEBER, M. Ensaios de Sociologia. Rio de Janeiro : Zahar.

\section{Outras fontes}

APROVALE. Disponível em: http:// www.valedosvinhedos.com.br/. Acesso em: 10.mai.2005.

BRASIL. MINISTÉRIO DO TRABALHO E EMPREGO. 2005. Relação Anual de Informações Sociais. CD-ROM.

MONDOVINO. 2004. Direção de Jonathan Nossiter. Paris: Diaphana Films. 1 DVD (135 min), color. 
THE MONDOVINO UPSIDE DOWN: TRANSFORMATIONS IN THE INTERNATIONAL WINE MARKET AND THE NEW WINEGROWING ENTREPRENEURIAL CLASS

\section{Mauro Roese}

The backdrop of this paper is the radical transformation of the entrepreneurial world in winegrowing that has been brought about by the entrance of new producers and the emergence of a new and now global culture of wine consumption. I analyze this transformation in the light of contributions made by a new Economic Sociology, as well as by social science perspectives on science and technology. The "popularization" of consumption is a reflection of the growth in the offer of quality wines as well as the price drop that has been made possible through the dissemination of technology and knowledge. This process has led to a loss of the "secrecy" that once surrounded the production of quality wines: what was once the privilege of a few producers and regions, kept under lock and key by family producers, has now become an object that can be apprehended and obtained through investments in technology and training. As a result, new producers of high quality wine have emerged in countries like Chile, Australia, South Africa and Brazil, among others. This transformation may be seen from two particular angles: one which focuses on the product's lost “aura” and with it, producers' and consumers' loss of privilege, and another which is linked to the social production of a new market including new producers and widening consumer access to quality wines. . This expansion of supply and consumption of quality wines has, nonetheless, been accompanied by the transformation of traditional winegrowers into cult objects that have become synonymous with exclusivity and distinction. The latter have thus become more restrictive and their wines, overvalued.

KEYWORDS: winegrowers; social construction of the market; Economic Sociology; Social Studies of Science and Technology; luxury market. 
LE MONDOVINO À L'ENVERS: LES TRANSFORMATIONS DANS LE MARCHÉ INTERNATIONAL DU VIN ET LA NOUVELLE ENTREPRISE VINICOLE

Mauro Roese

La profonde transformation du monde des entreprises vinicoles entrainée par l'arrivée de nouveaux producteurs et par l'avènement d'une nouvelle culture, désormais mondialisée, associée à la consommation du vin, c'est l'argumentation de fond de cet article. Telle transformation sera analysée à la lumière des contributions de la nouvelle Sociologie Économique, ainsi que des Études Sociaux de Sciences et Technologie. La "popularisation" de la consommation est une conséquence de la croissance de l'offre de vins de qualité et de la réduction du prix du produit, ce qui a été possible grâce à la 
diffusion de la technologie et des savoir-faire. Cela a entraîné la rupture du “secret” de la production du vin de qualité : ce qui autrefois était le privilège de quelques producteurs et régions, héritage sauvergadé à clé au sein des familles, devient l’objet de connaissance et peut être acquis au moyen des investissements dans la formation technologique. Par conséquent, de nouveaux producteurs de vin de qualité excellente sugissent dans des pays comme le Chili, l'Australie, l'Afrique du Sud, le Brésil, entre autres. Cette transformation peut être vue sous deux angles : celui de la fin "de l'aura" du vin, et en conséquence la perte du privilège de producteurs et de consommateurs, et celui de la production sociale d'un nouveau marché qui atteint de nouveaux producteurs et rend possible l'accès à d'autres consommateurs de vins de qualité. Pourtant, cette expansion de l'offre et de la consommation de vins de qualité fait en sorte que les vinicoles traditionnelles deviennent des objets de culte et synonymes d'exclusivité et de distinction. Devenant un groupe encore plus restreint, ces vinicoles ont vu leurs vins revalorisés davantage.

MOTS-CLÉS : entreprises vinicole ; construction sociale du marché ; Sociologie Économique ; Études Sociales de Science et de Technologie ; marché de luxe. 